\title{
Dynamic Analysis of Effect of Number of Balls on Rotor-Bearing System
}

\author{
Pyung Hwang and Van Trang Nguyen* \\ School of Mechanical Engineering, Yeungnam University \\ *Department of Mechanical Engineering, Yeungnam University \\ (Received April 27, 2013 ; Revised June 5, 2013 ; Accepted June 10, 2013)
}

\begin{abstract}
This paper presents a numerical model for investigating the structural dynamic response of an unbalanced rotor system supported on deep groove ball bearings. The aim of this work is to develop a numerical model for investigating the effect of the number of balls on the dynamic characteristics of the rotor ball bearing system. The fourth-order Runge-Kutta numerical integration technique has been applied. The results are presented in the form of time displacement responses and frequency spectra. The analysis demonstrates that the model can be used as a tool for predicting the nonlinear dynamic behavior of the rotor ball bearing system under different operating conditions. Moreover, the study may contribute to a further understanding of the nonlinear dynamics of rotor bearing systems.
\end{abstract}

Keywords - dynamic response, ball bearing, ball passage frequency, rotor bearing system

\section{Introduction}

Rotor dynamics is an important field of study that has many engineering applications in equipment such as turbines, jet engines, compressors, and electric motors. The prediction and analysis of the dynamic behavior of rotor systems are important because their rotating components possess large amounts of energy that might be transformed into vibrations. These vibrations not only affect the performance of the rotor system but may also cause serious damage to the rotating machinery system. Nonlinearities in rotor systems can be caused by many factors[1] such as Hertzian contact forces, internal radial clearances[2], stiffness coefficients, and rotor-based excitations. The aim of this work is to develop a numerical model for investigating the effect of the number of balls on the dynamic characteristics of the rotor ball bearing system. A twodegree-of-freedom system is considered with the assumption that there is no friction between the rolling

Author : phwang@yu.ac.kr elements and raceways of the ball bearings. The rolling elements are positioned symmetrically such that their motion is synchronized. The fourth-order Runge-Kutta numerical integration technique has been used to solve the system of nonlinear differential equations iteratively. The results presented here have been obtained from a large number of numerical integrations and are mainly in the form of time displacement responses and frequency spectra. The results provide a reliable model for predicting the dynamic behavior of a rotor ball bearing system under different operating conditions[15]. Such a model is of utmost importance in the design stages of rotating machinery systems.

\section{Problem Formulation}

Because a real rotor bearing system is very complicated and difficult to model[3-8], the analysis of the dynamic behavior of the system was based on the following assumptions while developing the mathematical model: 


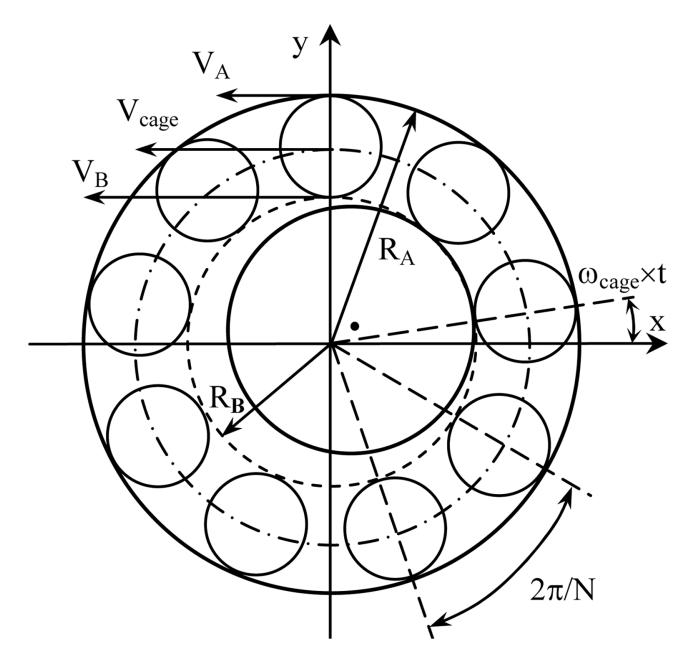

Fig. 1. Schematic diagram of ball bearing.

1. The torsional vibration of the rotor and the gyroscopic effects may be neglected and only transverse vibration of the rotor should be considered.

2. The outer race of the ball bearing is fixed to a rigid support, the inner race is fixed rigidly to the shaft, and there is no slippage of the balls.

3. A constant vertical radial force acts on the bearing.

4. Elastic deformation between the race and balls gives a nonlinear force deformation relationship, which is obtained by using Hertzian theory.

Zeillinger and Köttritsch[9] noted that additional damping usually occurs between the bearing's outer race and the housing. It is known that ball bearings have very low inherent damping, which is effective only for small vibration amplitudes[10]. Krämer[11] provided an estimation of the bearing damping, and Gupta et al. [12] indicated that the bearing coefficient of the ball bearing is within the range of 33.75$337.5 \mathrm{Ns} / \mathrm{m}$. A value of $\mathrm{c}=200 \mathrm{Ns} / \mathrm{m}$ was chosen.

As shown in Fig. 1, the tangent velocity of the contact point between the ball and the inner race $V_{A}$, and that between the ball and the outer race $V_{B}$, respectively, can be given by

$$
\begin{aligned}
& V_{A}=0 \\
& V_{B}=\omega_{B} \cdot R_{B}
\end{aligned}
$$

Because the outer race is assumed to be stationary, $\mathrm{V}_{\mathrm{A}}=0$. Therefore, the tangent velocity of the cage is

$$
V_{\text {cage }}=\frac{1}{2}\left(V_{A}+V_{B}\right)=\frac{V_{B}}{2}=\frac{\omega_{B} \times R_{B}}{2}
$$

Because the inner race is fixed to the shaft, $\omega_{\mathrm{B}}=\omega_{\text {rotor }}$ Then, the angular velocity of the cage is given by

$$
\omega_{\text {cage }}=\frac{V_{\text {cage }}}{\left(R_{A}+R_{B}\right) / 2}=\omega_{\text {rotor }} \times \frac{R_{B}}{R_{A}+R_{B}}
$$

The varying compliance frequency, or the ball passage frequency, can be expressed in terms of the cage speed times the number of balls, $\mathrm{N}$.

$$
\omega_{v c}=\omega_{\text {rotor }} \times N=\omega_{\text {rotor }} \times\left(\frac{R_{B}}{R_{A}+R_{B}} \times N\right)
$$

According to the Hertzian contact theory [Hertz, 1896], the local Hertzian contact force $F_{j}$ between the $\mathrm{j}^{\text {th }}$ ball and the race is given as follows [13]:

$$
F_{j}=K \times \delta_{j}^{1.5}
$$

The contact stiffness coefficient $\mathrm{K}$, can be given by the stiffness coefficient between the ball and each race [14], $\mathrm{k}_{\mathrm{i}}$ and $\mathrm{k}_{0}$ in series, as follows:

$$
K=\frac{1}{\left[\left(\frac{1}{k_{i}}\right)^{\frac{2}{3}}+\left(\frac{1}{k_{0}}\right)^{\frac{2}{3}}\right]^{\frac{3}{2}}}
$$

where $\mathrm{k}_{\mathrm{i}}$ and $\mathrm{k}_{0}$ can be determined using the elastic modulus, Poisson's ratio, and the curvature sum of the contact points, as described by Harris[13]. The geometrical properties of an NSK 6002 bearing are listed in Table 1 , where $\mathrm{K}=7.055 \times 10^{9}\left(\mathrm{~N} / \mathrm{mm}^{1.5}\right)$.

The inner race is supported by the rolling balls over an angular contact zone. Based on the Hertzian contact force between the inner and outer races and the ball, the total restoring force is the sum of the restoring force from each of the rolling elements. The "+" sign subscripts in equations (8) and (9) signify the step change in the restoring force expression and models the nonlinearity in the radial clearance. If the expression inside the brackets is greater than zero, the ball at the angular location $\theta_{1}$ is within the angular 
Table 1. Geometrical properties of NSK 6002 bearing

\begin{tabular}{lc}
\hline \hline Radial clearance $(\gamma)$ & $1 \mu \mathrm{m}$ \\
Radial load $(\mathrm{W})$ & $6 \mathrm{~N}$ \\
Mass of rotor $(\mathrm{m})$ & $1.2 \mathrm{~kg}$ \\
Damping factor $(\mathrm{c})$ & $200 \mathrm{Ns} / \mathrm{m}$ \\
Force due to unbalance rotor $\left(\mathrm{F}_{\mathrm{u}}\right)$ & $0.9 \mathrm{~N}$ \\
Number of the balls, $(\mathrm{N})$ & $8,9,10,11$ \\
Inner race radius, $\left(\mathrm{R}_{\mathrm{B}}\right)$ & $9.37 \mathrm{~mm}$ \\
Outer race radius, $\left(\mathrm{R}_{\mathrm{A}}\right)$ & $14.43 \mathrm{~mm}$ \\
Ball diameter, $(\mathrm{D})$ & 4.76 \\
Poisson's ratio & 0.3 \\
Elastic modulus, $(\mathrm{E})$ & $2.0 \times 10^{11}\left(\mathrm{~N} / \mathrm{mm}^{2}\right)$ \\
Time step $(\Delta \mathrm{t})$ & $10^{-5} \mathrm{~s}$ \\
\hline
\end{tabular}

contact zone and it is loaded, giving rise to a restoring force. If the expression within the brackets is negative or zero, the ball is not in the load zone and the restoring force is set to zero. Therefore, the contact force between the $\mathrm{j}^{\text {th }}$ ball and the inner race can be expressed as

$$
\begin{aligned}
& F_{x}=\sum_{j=1}^{N} K\left[\left(x \cos \theta_{j}+y \sin \theta_{j}\right)-\gamma\right]_{+}^{1.5} \cos \theta_{j} \\
& F_{y}=\sum_{j=1}^{N} K\left[\left(x \cos \theta_{j}+y \sin \theta_{j}\right)-\gamma\right]_{+}^{1.5} \sin \theta_{j}
\end{aligned}
$$

Because the inner race is moving at the speed of the shaft and the ball center at the speed of the cage, the contact angle $\left(\theta_{\mathrm{i}}\right)$ is given by

$$
\theta_{j}=\frac{2 \pi}{N}(j-1)+\omega_{\text {cage }} \times t, j=1, \ldots, N
$$

The mathematical model takes into account the sources of nonlinearities in the rotor bearing system. After obtaining the inertia, ball bearing force, damping force, and constant vertical force acting on the inner race, the dynamic equations of the system are established as follows:

$$
\begin{aligned}
& m \ddot{x}+c \dot{x}+\sum_{j=1}^{N} K\left[\left(x \cos \theta_{j}+y \sin \theta_{j}\right)-(\gamma)\right]_{+}^{1.5} \cos \theta_{j} \\
& =W+F_{u} \cos \left(\omega_{\text {rotor }} \times t\right)
\end{aligned}
$$

$$
\begin{aligned}
& m \ddot{y}+c \dot{y}+\sum_{j=1}^{N} K\left[\left(x \cos \theta_{j}+y \sin \theta_{j}\right)-(\gamma)\right]_{+}^{1.5} \sin \theta_{j} \\
& =F_{u} \sin \left(\omega_{\text {rotor }} \times t\right)
\end{aligned}
$$

\section{Results and Discussion}

The nonlinear governing equations of motion (11) are solved by the fourth-order Runge-Kutta numerical integration technique to obtain the axial and radial displacement of the rolling element and the shaft. The initial conditions are set to $\mathrm{x}_{0}=10^{-6}(\mathrm{~m}), \mathrm{y}_{0}=10^{-6}(\mathrm{~m})$, $\mathrm{x}^{\prime}{ }_{0}=0, \mathrm{y}^{\prime}{ }_{0}=0$, and $\mathrm{K}=7.05 \times 10^{9}\left(\mathrm{~N} / \mathrm{m}^{1.5}\right)$. To observe the effect of the number of balls, the time displacement response and frequency domain vibrations of the shaft rotor bearing system are obtained to determine the dynamic behavior of the system[16].

The number of balls is one of the key factors affecting the dynamic characteristics of a rotor system. Fig. 2(a)-2(d) shows the response at a speed of 6,000 rpm with 8 balls. The varying compliance frequency $\left(\omega_{v c}\right)$ at $6,000 \mathrm{rpm}$ is $315 \mathrm{~Hz}$. For the horizontal displacement response, the peak amplitude of vibration appears at twice the varying compliance frequency $2 \omega_{\mathrm{vc}}=630 \mathrm{~Hz}$ with three subharmonics, which appear at $\omega_{\mathrm{vc}}=315 \mathrm{~Hz}, \omega_{\mathrm{vc}} / 5=62 \mathrm{~Hz}, 6 \omega_{\mathrm{vc}} / 5=$ $378 \mathrm{~Hz}$. The peak amplitude is $0.308 \mu \mathrm{m}$ at $2 \omega_{\mathrm{vc}}=630$ $\mathrm{Hz}$ for the vertical displacement response. The peak amplitude of vibration is $0.835 \mu \mathrm{m}$ at $\mu_{\mathrm{vc}}=315 \mathrm{~Hz}$. The major peaks are at $\mu_{\mathrm{vc}} / 5=62 \mathrm{~Hz}$ and $2 \mu_{\mathrm{vc}}=630 \mathrm{~Hz}$.

Fig. 2(e)-2(h) shows the response with 9 balls. The natural frequency coincides with the varying compliance frequency $\left(\omega_{\mathrm{vc}}=354 \mathrm{~Hz}\right)$. The peak amplitude is $0.105 \mu \mathrm{m}$ in the horizontal direction. For the horizontal displacement response, the major peak amplitudes of vibration appear at $\omega_{\mathrm{vc}} / 2=180 \mathrm{~Hz}, 3 \omega_{\mathrm{vc}} / 2=534 \mathrm{~Hz}$, and $2 \omega_{\mathrm{vc}}=708 \mathrm{~Hz}$. The peak amplitude is $0.373 \mu \mathrm{m}$ in the vertical direction at $\omega_{v c}=354 \mathrm{~Hz}$. The other major peaks for vertical displacement responses are at $\omega_{\mathrm{vc}} / 2$ $=180 \mathrm{~Hz}, 3 \omega_{\mathrm{vc}} / 2=534 \mathrm{~Hz}$, and $2 \omega_{\mathrm{vc}}=708 \mathrm{~Hz}$.

When the number of balls increases to 10 balls, as shown in Fig. 3(a)-3(d), the peak amplitudes for horizontal and vertical displacement response are at 

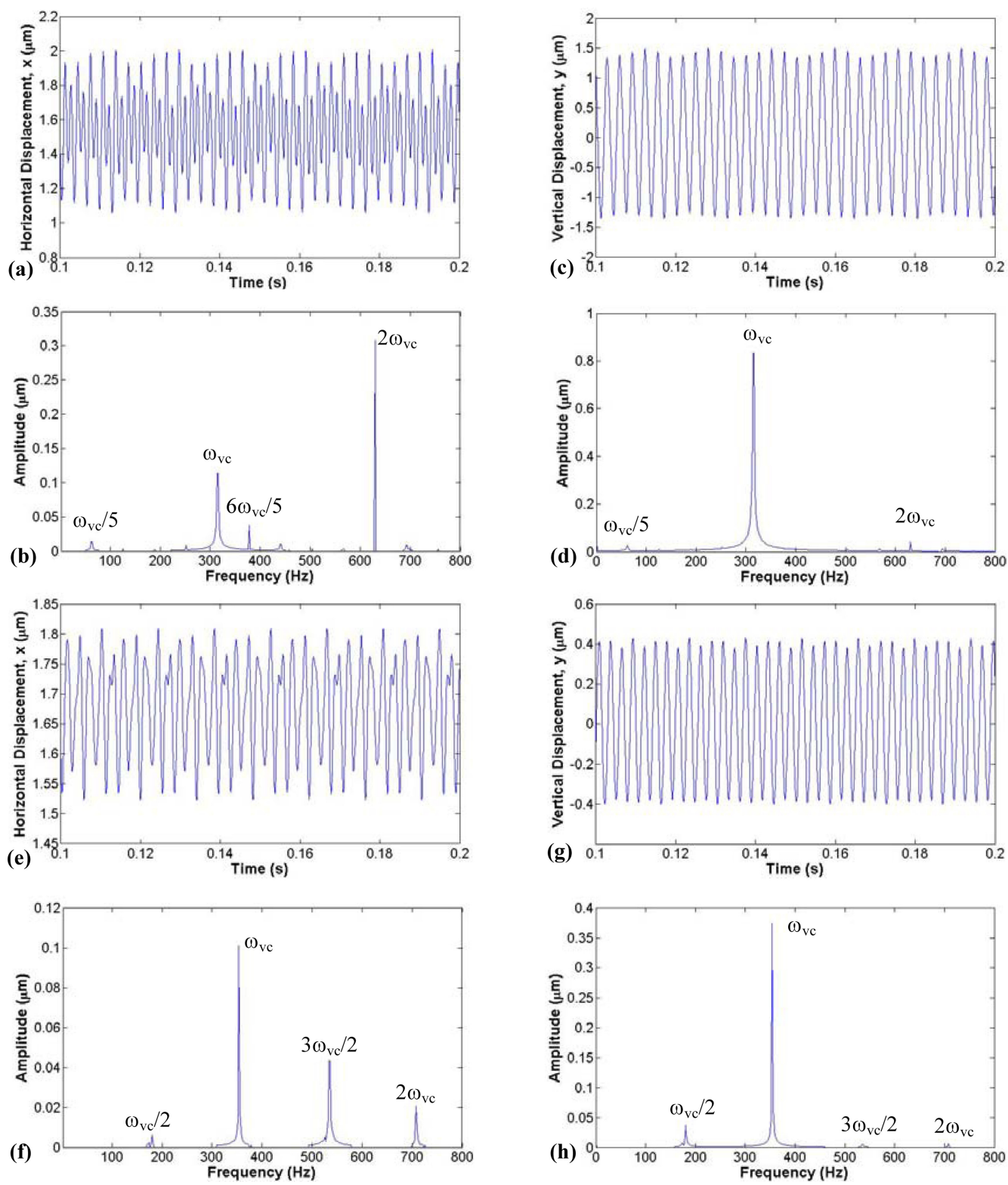

Fig 2. (a), (b) Horizontal displacement response with time, and FFT for horizontal displacement response at $\mathbf{N}$ $=8$, respectively. (c), (d) Vertical displacement response with time, and FFT for vertical displacement response at $\mathbf{N}=8$, respectively. (e), (f) Horizontal displacement response with time, and FFT for horizontal displacement response at $\mathbf{N}=9$, respectively. (g), (h) Vertical displacement response with time, and FFT for vertical displacement response at $\mathrm{N}=9$, respectively.

0.10 and $0.231 \mu \mathrm{m}$, respectively. The other major peaks for horizontal and vertical displacement responses are at $2 \omega_{\mathrm{vc}}=788 \mathrm{~Hz}$. Subharmonics seem to be disappearing, as shown in Fig. 3(b) and 3(d).
Hence, the nonlinear dynamic responses are found to be associated with the varying compliance frequency.

For the response with 11 balls, the natural frequency coincides with the varying compliance frequency $\omega_{v c}$ 

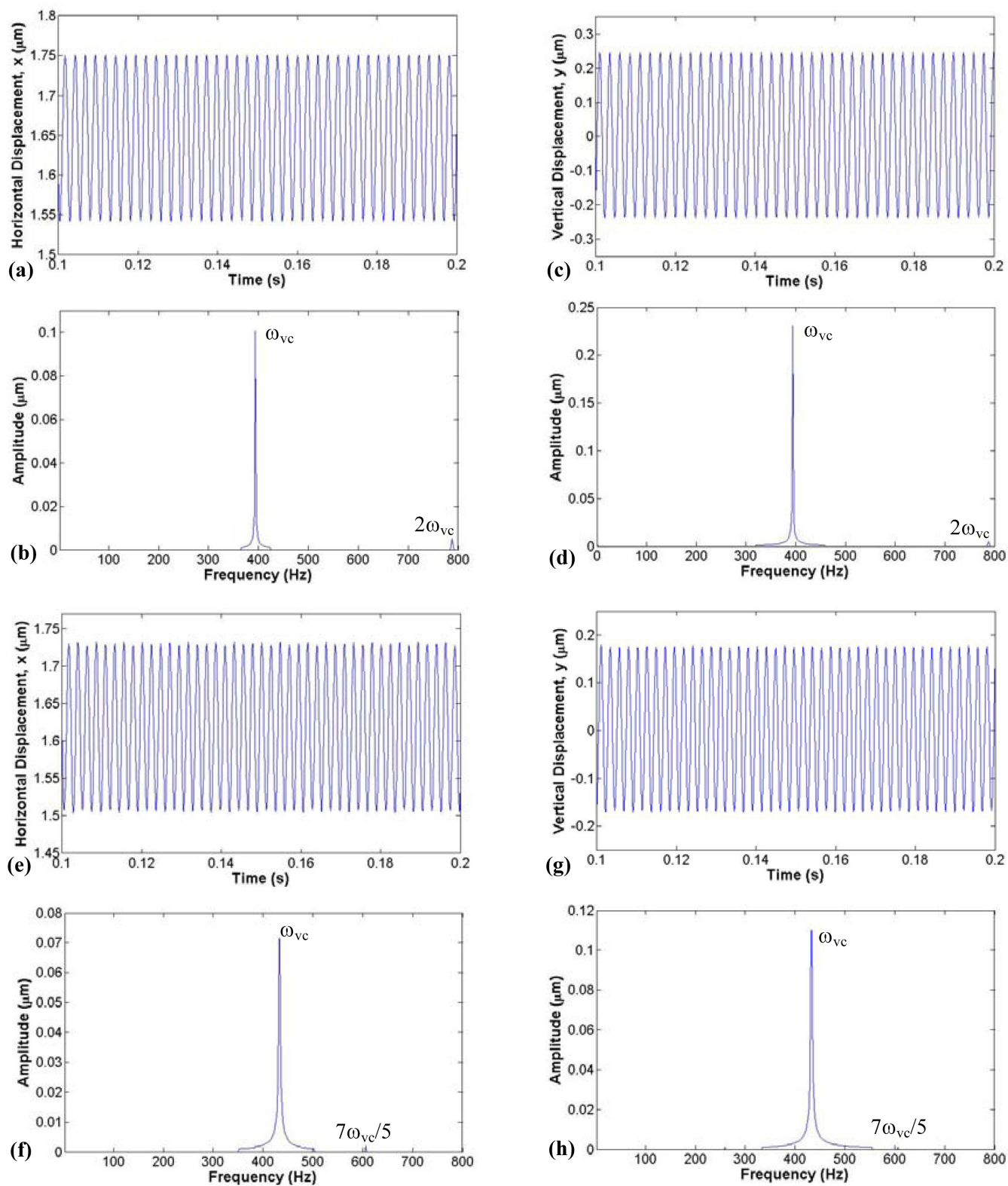

Fig. 3. (a), (b) Horizontal displacement response with time, and FFT for horizontal displacement response at N $=10$, respectively. (c), (d) Vertical displacement response with time, and FFT for vertical displacement response at $\mathrm{N}=10$, respectively. (e), (f) Horizontal displacement response with time, and FFT for horizontal displacement response at $\mathrm{N}=11$, respectively. (g), (h) Vertical displacement response with time, and FFT for vertical displacement response at $\mathrm{N}=11$, respectively.

$=433 \mathrm{~Hz}$. The peak amplitudes for horizontal and vertical displacement responses are 0.071 and $0.11 \mu \mathrm{m}$, respectively.

The other major peaks for the horizontal and vertical displacement responses are at $7 \omega_{\mathrm{vc}} / 5=606 \mathrm{~Hz}$, as shown in Fig. 3(f) and 3(h). It is seen from the solutions that the effect of the number of balls by certain conditions, the amplitude responses are 
modulated. For fewer balls, the peak amplitudes of vibrations at the varying compliance frequency are more significant. The main reason for this is that increasing the number of balls increases the number of balls supporting the shaft and therefore increases the system stiffness and reduces the vibration amplitude in the vibration spectrum.

\section{Conclusions}

In this study, a two-degree-of-freedom, nonlinear model of a rotor ball bearing system has been developed to obtain nonlinear vibration responses by varying the number of balls. Nonlinear analysis of this model was performed numerically using the fourthorder Runge-Kutta integration method.

The results show that the dynamic characteristic behavior of the system is sensitive to small variations in the system parameters. Increasing the number of balls increases the number of balls supporting the shaft and therefore, increases the system stiffness and reduces the vibration amplitude. Hence, the number of balls is an important parameter for the vibration analysis of a rotor bearing system and should be considered at the design stages of rotating machinery systems. The model can be used as a tool for predicting the nonlinear dynamic behavior of rotor ball bearing systems under different operating conditions. Moreover, the study may contribute to a further understanding of the nonlinear dynamics of rotor bearing systems.

\section{Nomenclature}

$m: \quad$ Mass of rotor, $\mathrm{kg}$

$c: \quad$ Equivalent viscous damping factor, $N s / m$

$F_{d} / F_{y}$ : Hertzian contact force in horizontal/vertical direction, $N$

$F_{u}: \quad$ Force due to unbalance rotor, $N$

$K: \quad$ Hertzian contact stiffness, $N / \mathrm{m}^{3 / 2}$

$N$ : Number of balls

$R_{B}: \quad$ Inner race radius, $m m$

$R_{A}$ : $\quad$ Outer race radius, $\mathrm{mm}$ $t: \quad$ Time, $s$

$V_{\text {cage }}$ : Translational velocity of cage center, $\mathrm{mm} / \mathrm{s}$

$V_{a}: \quad$ Translational velocity of inner race, $\mathrm{mm} / \mathrm{s}$

$V_{b}$ : Translational velocity of outer race, $\mathrm{mm} / \mathrm{s}$

$W$ : $\quad$ Radial load, $N$

$\gamma: \quad$ Internal radial clearance, $\mu m$

$\omega_{\text {rotor }}:$ Angular speed of rotor, $\mathrm{rad} / \mathrm{s}$

$\omega_{\text {cage }}:$ Angular speed of cage, $\mathrm{rad} / \mathrm{s}$

$\omega_{A}: \quad$ Angular speed of inner race, $\mathrm{rad} / \mathrm{s}$

$\omega_{B}: \quad$ Angular speed of outer race, $\mathrm{rad} / \mathrm{s}$

$\theta_{i}$ : Angular location of $\mathrm{i}_{\text {th }}$ rolling element, $\mathrm{rad} / \mathrm{s}$

\section{Acknowledgment}

This research was supported by the Yeungnam University Research Fund Program.

\section{References}

1. F. Ehrich, "Observations of Nonlinear Phenomena in Rotordynamics," Journal of System Design and Dynamics, Vol. 2, No. 3, pp. 641-651, 2008.

2. M. Cheng, G. Meng, and B. Wu, "Nonlinear Dynamics of a Rotor-ball Bearing System with Alford force," Journal of Vibration and Control, Vol. 18, No. 1, pp. 17-27, 2011.

3. S. Fukata, E.H. Gad, T.A. Kondou, and H. Tamura, "On the Radial Vibrations of Ball Bearings (Computer Simulation)," Bulletin of the JSME, Vol. 28, pp. 899-904, 1985.

4. F.M.A. El-Saeidy, "Finite Element Modeling of Rotor-shaft-rolling Bearing System with Consideration of Bearing Nonlinearities," Journal of Vibration and Control, Vol. 4, pp. 514-602, 1998.

5. M. Tiwari, K. Gupta, and O. Prakash, "Experimental Study of a Rotor Supported by Deep Groove Ball Bearing," International Journal of Rotating Machinery, Vol. 8, No. 4, pp. 243-258, 2002.

6. M. Tiwari, K. Gupta, and O. Prakash, "Effect of Radial Internal Clearance of a Ball Bearing on the Dynamics of a Balanced Horizontal Rotor," Journal of Sound and Vibration, Vol. 238, No. 5, pp. 723756, 2000.

7. F.P. Wardle and S.Y. Poon, "Rolling Bearing Noise, Cause and Curve," Chartered Mechanical Engineering, pp. 36-40, 1983.

8. F.P. Waardle, "Vibration Forces Produced by Waviness of the Rolling Surfaces of Thrust Loaded Ball 
Bearings. Part I: Theory," Proceeding of the IMechE, Vol. 202(C5), pp. 305-312, 1988.

9. R. Zeillinger and H. Köttritsch, "Damping in a Rolling Bearing Arrangement," Evolution, 1/96 (1996).

10. P. Lewis and S.B. Malanoski, "Rotor-bearing Dynamics Design Technology, Part IV: Ball Bearing Design Data," AFAPL-TR-65-45 (1965).

11. E. Krämer, "Dynamics of Rotor and Foundations," Springer-Verlag, New York (1993).

12. T.C. Gupta, K. Gupta, and D.K. Sehgal, "Nonlinear Dynamics and Chaos of an Unbalanced Flexible Rotor Supported by Deep Groove Ball Bearings with Radial Internal Clearance," IUTAM Symposium on Emerging Trends in Rotor Dynamics, (2011).

13. T.A. Harris, "Rolling Bearing Analysis," $4^{\text {th }}$ Edition,
John Wiley \& Sons, Inc., New York, 2001.

14. G.H. Jang and S.W. Jeong, "Nonlinear Excitation Model of Ball Bearing Waviness in a Rigid Rotor Supported by Two or more Ball Bearings Considering Five Degrees Of Freedom," Transactions of the ASME, Vol. 124, 2002.

15. P. Hwang and V.T. Nguyen, "A Study on Dynamic Analysis of Rotor-bearing System with the Effect of Number of Balls," Proceedings of KSTLE 56 ${ }^{\text {th }}-2013$ Spring Conference, Seoul, Korea, 2013.

16. P. Hwang, G. Pan, and P. Khan, "Natural Frequency Analysis of Sliders and Head/disk Interaction Detection by Acoustic Emission," KSTLE International Journal, Vol. 5, No. 1, pp. 28-31, 2004. 